\title{
Guanxi or What is the Chinese for Relational Theory of World Politics
}

Emilian Kavalski*

\author{
Li Dak Sum Chair Professor in China-Eurasia Relations and \\ International Studies, School of International Studies, University \\ of Nottingham Ningbo China, 199 Taikang East Road, Ningbo \\ 315100, China
}

*Email: emilian.kavalski@gmail.com

Accepted 2 April 2018

\begin{abstract}
The phenomenon of China's rise has urged some to look for International Relations (IR) theories with 'Chinese characteristics'. A number of these have been associated with the 'relational turn'. Yet, attempts to bring the Anglophone and the Sinophone strands of the relational turn have failed to transcend the bifurcating metanarrative of the mainstream. To rectify this trend, the analysis engages the literatures on guanxi, the relational turn, and Chinese IR and develops a normative claim about the underlying relationality of knowledge production in post-Western IR. The contention is: (i) that the criticism of substantialism offered by the Anglophone literature on the relational turn fails to overcome its Eurocentrism; (ii) that by subscribing to the epistemic duality of the West vs. the non-West, the Sinophone literature has aborted the political promise of the concept of guanxi. The study deploys guanxi to amplify the intrinsic relationality both of global life and the realms of IR.
\end{abstract}


Having perused the present translation of the scriptures in Chinese, I find it exceedingly verbose, containing much foreign phraseology, so contrary to the usual style of our books that the Chinese cannot thoroughly understand the meaning. It ought to be known that, in the Chinese, phrases have a certain order, and characters a definite application, which cannot be departed from with propriety... Now it appears to me, that the present version is in Chinese words, but in many respects arranged according to the English idiom (emphasis added). In a translation, the sense ought certainly to be given, according to the original; but the style should be conformable to native models: thus everyone will take up the book with pleasure, and read it with profit.

Chooh Tih-Lang (quoted in Medhurst, 1838, p. 549)

\section{Introduction}

How China thinks and in what ways its history and traditions inform the idiosyncrasies of China's international outlook have grown into a cottage industry both in International Relations (IR) and across the full spectrum of the humanities and social sciences (Pan, 2012; Horesh and Kavalski, 2014). It appears that at the heart of these investigations is China's positioning in European intellectual imagination as the ultimate Other or what Michel Foucault called heterotopia - a disturbing place, whose difference 'undermines language'. China becomes 'the Other country' not merely because of its location on the opposite end of the Eurasian landmass, but also because it represents 'a culture entirely devoted to the ordering of space, but one that does not distribute the multiplicity of existing things into any of the categories that make it possible for us to name, speak, and think' (Foucault, 2002, p. xix). In this setting, it should not appear surprising that the promulgation of Chinese concepts into the discourses of IR appears not only to question 'the very "constitutional structures", of the discipline (Carlson, 2010, p. 96), but also calls on IR theory to embark on the road less traveled of encountering the multiverse of relations animating global life.

It would therefore make sense to set off on this journey by recalling the etymology of the term theory. The Greek word theoria meant ' $\mathrm{a}$ journey or a pilgrimage', involving a willingness to travel to foreign locales that can then simultaneously inform and transform the 'home' 35 of the traveller (Nightingale, 2004, pp. 4-9). Equally significantly, by 
providing a potent form of social interactions, the itinerant performativity of such theoretical travels seems to have played an important role in shaping IR by providing opportunities for 'constant reframing and reconfigurations of participants towards each other', which allowed the ancient Greeks to 'imagine and exploit forms of inter-polis contact' (Kowalzig, 2005). By extension, theorizing - as the 19th-century Chinese interpreter Chooh Tih-Lang suggests in the epigraph becomes a relational process of irruptive translation that brings in dialogue the form and substance of the languages and experiences of diverse and infinitely complex worlds. A complex 'translingual practice' (Liu, 1995), such relational knowledge production belies an openness to the other which does not merely intertwine identity and alterity but makes 'the act of translating a process of continuous dislocation' (Kavalski, 2018a, p. 6). Yet, in lieu of the messiness and dislocation associated with such itinerant translation, IR theory seems to recognize 'other' forms of theory-building only to the extent that they can be 'arranged according to the English idiom'. As such, while the 'Anglosphere' of IR knowledge production may claim to be global in its reach, it is less so in its cultural underpinnings (Vucetic, 2011); in fact, it seems to offer non-Anglophone scholars only temporary 'worker's visas' rather than granting them 'the rights to "full disciplinary citizenship"' (Beier, 2005, p. 62).

So how can China's rise be grasped if it is to be studied only in the language of and from the perspectives of a small fraction of the IR community, while silencing the voices of all those who are unfamiliar with it? The suggestion of this article is that IR theorizing needs to learn and employ different languages if it is to offer a richer and more nuanced account of the complex and heterogenous global life it seeks to comprehend. Such an endeavor should resonate with much of what the mainstream already admits theorizing in IR is about - namely, the identification, observation, explanation, and understanding of patterns by looking at the record of what happens when international actors come together in space and time. Perhaps, some would be surprised that no other than Kenneth Waltz has postulated that theorization is an inherently relational interpretative endeavor. As he put it, IR theo- 35 ries 'convey a sense of unobservable relations of things. They will be about connections and causes by which sense is made of things observed' (Waltz, 1979, p. 9). Waltz ascertained that such sense-making is 
transactional at the very level of 'the observer' and 'the observed'. Namely, IR theories are not objective representations of the world, but 'artistic creations, shaped by the taste and style of a single hand [that of the theorist undertaking the explanation and understanding]' (Waltz, 1979, p. 10; emphasis added). Thus, it is creativity and improvization rather than the provision of prescriptive or proscriptive solutions that promise to heal the habits of control, manipulation, and exploitation associated with IR's insistence on the separation between subject and object, knower and known, self and other, mind and matter (Kavalski, 2018b). While the insistence that IR theory is a relational construct distinct from 'the reality of international practice' might appear radical to some (Waltz, 1979, p. 68), it merely draws attention to the itinerant and translational nature of theorizing. Such framing betrays the complex, eclectic, and nonobjective blend of cultural universals and culturally specific patterns of social relations underpinning the encounter with global life. The point is that Anglophone IR cannot continue to ignore the flexibilities, contingencies, and transformative possibilities engendered by the encounter with other lifeworlds and knowledges, so that it can sustain the integrity of an outlook committed to the analysis of discrete atomistic actors whose behavior is predetermined by the distribution and balance of power.

This study therefore intends an interpretative theoretical journey into Sinophone concepts and definitions of the international with the intention to explore whether they indeed are so heterotopic as to be unworthy of translation for IR theorizing. It has to be stated at the outset that the focus on guanxi (traditional: 關係 simplified: 关系) is not entirely coincidental. It is one of the words that make up the Chinese term for 'International Relations' - guoji guanxi (traditional: 國際關係 simplified: 国际关系). In this respect, it should appear surprising that there has been so little attention to the meaning and content of the terms that go into the making of the Chinese phrase for IR. What is particularly telling is that one does not have to be fluent in Chinese to encounter the complex texture of the term - for instance, cognate social scientific fields such as Sociology, Cross-Cultural Communication, and Psychology offer a rich repository of information about the meaning and practices of guanxi. The first part of this article draws on these conversations to tease out the content and practices of this term, as well as its implications for IR theory and practice. The 
attention is to the ways in which the affordances of relationality are foreshadowed by the engagement with the concept of guanxi. The second part of the article points to some of the ways in which the concept of guanxi informs nascent modes of relational theorizing in IR, before discussing the normative aspects of this proposition in the 5 conclusion.

The necessary caveat is that the labels of Anglophone and Sinophone are used in this study as operational shorthand, recognizing the existence of two distinct 'discourse communities' in IR with separate (usually, local) Chinese and (global) English-speaking audiences 10 (Mokry, 2016, pp. 135-159). The acknowledgment of such separate discourse communities does not intend to reiterate essentializing ascriptions of Western or Chinese characteristics. Instead, by demonstrating that there is more than one way of seeing, hearing, and responding, the reference to Anglophone and Sinophone communities calls on IR 15 to overcome the 'geopolitics of its knowledge-production' by actively engaging in translation, while remaining cognizant of the politics of language in the study of global life (Mignolo, 2002; D'Aoust, 2012; Kavalski, 2018c; Vale, 2014). At stake here is the ability to engage other ontologies as a way of learning different ways to observe and encounter the world, ourselves, and the problems that embroil us, and to put such alternatives into a nuanced comparative conversation with more familiar critical political lexicons and procedures inherited from Anglophone academic scholarship (Kavalski, 2017, p. 166). On the one hand, such theorizing as itinerant translation discloses the world as a multiversal space where alternative realities can and do coexist and have done so for quite some time. On the other hand, such relational knowledge production mandates tolerance of at least as much diversity and contradictions as evident in the social relations being narrated (Kavalski, 2018a, p. 5). Thus, guanxi is deployed here as a heuristic device revealing the infinite capacity of (international) interactions to create and construct multiple worlds rather than as a term illustrating the actual practices of Chinese foreign policy. While such connections are clearly there (especially, in places like Central Asia and in initiatives such as the 'One Belt, One Road' [OBOR]), the aim is to disclose an 35 epistemically and ontologically relational theory of IR made possible by the encounter with guanxi. 
In particular, the intention is to make an analytical contribution to the understanding and explanation of the post-Western flavors of relationality in IR rather than illustrate how China has been able to gain a tremendous amount of goodwill and political capital in the Global South. The point is that IR knowledge - just like any other knowledge - can neither pretend to be monological, nor exists in isolation; rather to know one thing, IR scholars not only have to know and be curious about a lot of other things, but also be willing to engage them (and countenance others engaging) in imagining, questioning, advancing, and co-creating the range of 'the plausible' practices and theories for 10 their explanation and understanding (Kavalski, 2017, pp. 161). Therefore, this is an article not about the international practices of China, but about the ways in which Sinophone concepts - such as guanxi - can aid the disclosure of alternative and, especially, relational modes of IR theorizing. Many scholars have bemoaned the unending demand by Anglophone IR to constantly qualify, bracket, and signpost their engagement with non-Western ideas because they stick out as 'concepts that do not fit' (Tickner, 2003), while the tendency to deploy Western concepts - such as sovereignty, anarchy, democracy - in the abstract (not least because of their presumed universalism) has never seemed to trouble Anglophone IR and in fact has been 'fetishized' by its interlocutors (Chowdhry, 2007, p. 106; Kavalski, 2009, pp. 1-18). While this article does not suggest that post-Western IRs must engage in reverse 'deflection' (Morefield, 2014), it insists that IR can have (and, in fact, sorely needs) a culturally attuned and contextually verdant engagement with ideas independent of the practices of the governments that administer the territories and societies from which such ideas originate. The concluding section evokes these registers of worlding mutuality by elaborating the ways in which guanxi can help transcend both the expected and the Western/non-Western bifurcation that dominates so much of the literatures both on relationality and IR theory. The proposition of a nonbinary itinerant theorizing embraces the political promise of engaging creatively with the contradictions, challenges, and opportunities of an entangled and unpredictable global life. By uncovering a range of alternative stories that need to be heard, 35 guanxi appears to provide a plausible answer to both the deconstruction of the hegemony of Eurocentrism and the reconstruction of the IR epistemic community. It is through the itinerant translation of such 
relational knowledge production that IR can learn to be more democratic and truly global.

\section{Guanxi: what's in a name?}

Perhaps, one of the most memorable images from the diplomatic rapprochement between the United States and the People's Republic of China in the 1970s is the opulent banquet that President Richard Nixon and Premier Zhou Enlai shared at the Great Hall of the People. In front of the whirring cameras of international media, one of the most important realignments of the Cold War period was taking place around tables brimming with sumptuous Chinese culinary delights dished out for the Americans by their Chinese hosts. As the food historian Andrew Coe reveals, Chairman Mao had personally instructed Zhou Enlai to restore connections with the noncommunist world by wining and dining foreign leaders (Coe, 2009). At the banquet in the Great Hall of the People, Premier Zhou presented Nixon with a bottle of moutai (distilled Chinese liquor) which he had kept for over 30 years, while Mao personally added a dish of hongshao huashi (a soy-sauce-braised herring tail) to the lunch the two had on the previous day because of its symbolism for facilitating difficult conversations (Kavalski, 2018a, p. 69). It seems therefore that in order to end the country's self-imposed isolation, the Chinese leadership was resorting to an age-old practice embedded in the traditions that their cultural revolution intended to eradicate - namely, guanxi.

While several recent IR studies have made reference to the term guanxi (Kavalski, 2012, 2016, 2018a; Huang and Shih, 2014; Uemura, 2015; Pan, 2016), the analysis provided here is distinguished for treating guanxi not just as an explanatory device for China's diplomacy, but as a key to a relational knowledge production and action in IR. Also, none of the current IR accounts have engaged the complex history and etymology of this term. It is therefore necessary to offer a brief account of the meanings that this term has come to acquire as the background to its deployment in IR's knowledge production. To begin with, guanxi appears to be one of those essentially contested concepts, whose meaning and practices are anything but clear cut and universally accepted (Hwang, 1987). Almost all commentators acknowledge the Confucian underpinnings of such practices, although 35 many also assert that guanxi has become a shorthand for patterns of 
thought and behavior predating the time and teachings of Confucius. Rather than a constraining straitjacket, such intellectual legacy seems to have provided an enabling platform for contingent innovation after all, Confucius himself acknowledged the entrepreneurial endeavor of his efforts by calling himself a 'co-worker with antiquity' (Ford, 2010, p. 17). More often than not, guanxi is understood to denote the establishment and maintenance of 'an intricate and pervasive relational network' engendered by the practice of unlimited exchange of favors between its members and bound by reciprocal obligation, assurance, and mutuality (Pye, 1982, p. 882; Kavalski, forthcoming).

In this setting, banquet-giving - as both Henry Kissinger and Nixon discovered in the early 1970 s - performs a crucial role in engendering and sustaining positive sentiments among participants, who might initially be inimical to one another. While not unique to Chinese culture, the practices of food-sharing play a distinct role in informalizing interactions - especially, in transforming diplomatic relations into interpersonal ones and drawing foreign representatives into establishing friendship ties which then make them subject to the 'blandishments and pressures of the Chinese social order' (Walker, 2012, p. 495). Solomon (1975, p. 53) observed at the time that 'as the common [Chinese] saying goes, if you eat the things of others you will find it difficult to raise your hand against them'. And, indeed, the practice of food-sharing - especially, the opulent Peking duck dinners that Kissinger and Zhou Enlai shared during their secret negotiations in the run-up to the Mao-Nixon meeting - appears to have played an important role in lubricating the SinoAmerican relationship. While the American diplomats commented (and commended) the sophistication and deftness with which Zhou Enlai was introducing and serving the various dishes, such meals both mellowed the tensions and allowed the two sides to embark on the process of changing their preconceptions about one another (Coe, 2009, 30 pp. 228-230). The record of these diplomatic banquets illustrates the key underlying feature of these kind of interactions (either in interpersonal or international relations) - the provision of a friendly feeling, which personalizes the social process, infuses it with a sense of obligation 'to give, to receive, and to repay', and ensures participation in 'the 35 games of guanxi' (Solomon, 1995, p. 152).

While guanxi has been labeled as 'the lifeblood of all things Chinese - business, politics, and society,' 'one of the most fundamental aspects 
of Chinese political behaviour', the 'key to the Chinese way of thinking', and a central philosophical concept that 'reflects the Chinese way to know about reality (ontology), the Chinese way to interpret reality (phenomenology), and the Chinese values about humanity (axiology)', its widespread usage appears to be of very recent provenance (in Kavalski, 2018a, pp. 70-71). In particular, guanxi's rise to prominence seems to be closely associated with social, political, and economic processes set in motion during the second half of the 20th century across the 'Chinese commonwealth' - in Mainland China, Taiwan, Hong Kong, Macau, and Singapore, as well as the Sinophonic diaspora around the globe (Gold et al., 2002, pp. 13-14). In this setting, guanxi has acquired positive connotations (associated with bottom-up empowerment) and negative flavors (associated with graft), both of which (i) arise from the propensity of its practices to subvert established structures of authority and (ii) reflect an idiosyncratic en- 15 counter between tradition and modernity in the sociopolitical and economic development of the state (Yang, 2002; Ledeneva, 2008).

Probably, the central Confucian inflection of guanxi is the deontological commitment to act in accordance with social demands and expectations. It needs to be reiterated that these commitments are not 20 constraining, nor do they deny spontaneity and improvization; instead, they merely reflect the dependence on and persistence of relationships - both of which entail a 'responsibility to respond to the reactions of and needs of others' (emphasis added) (Weakland, 1950, p. 365). In the Confucian framing, guanxi-practices are embedded in the four virtues 25 (benevolence $[\mathrm{ren}]$, appropriateness $[y i]$, propriety $[l i]$, and wisdom $[z h i]$ ) and emphasize reciprocal obligations framed by five hierarchical social relations: (i) ruler-subject; (ii) father-son; (iii) husband-wife; (iv) older brother-younger brother; (v) elder friend-junior friend (Tu, 1985, p. 162). It is often overlooked that these relations provide a framework for acquiring knowledge about global life 'by going beyond the self and reaching out to the world' (Fei, 1992, p. 67). The practice-oriented social norms engendered by the four virtues intend a modicum of predictability in the encounter with 'the unknown out there' by evincing meaningful patterns across the contingency of human sociality, because 35 'people who are so enmeshed in customary norms cannot behave in any other way' (Fei, 1992, p. 43). Such sense-making is premised on (i) the willingness to expand one's outlook 'from the self to the family, 
from the family to the state, and from the state to the world (tianxia)' (Fei, 1992, p. 66); and (ii) the practice of engaging the experience of others in ways that are simultaneously unprecedented for, yet meaningfully continuous with, the specific social context (Jenco, 2016, p. 16).

At the same time, framed by metaphors of kinship, the roles outlined by the five hierarchical social relations come with certain duties that each side needs to enact. If those obligations are not fulfilled that is, if favors done are not reciprocated - the reputation of the transgressor is tarnished. Thus, the implicit threat of social sanctions is often sufficient to ensure that favors are repaid, that obligations are 10 met, and that relationships are honored. It is important to note that in a Confucian context, even though guanxi relations are asymmetrical, they are nevertheless volitional - in other words, the structure of hierarchy should not be misunderstood as giving one side influence over the other. On the contrary, the very nature of reciprocal obligation belies its constraining power on both sides of the guanxi tie (Barbalet, 2015, p. 1046). In fact some have suggested a certain paradox of power in guanxi, where owing to the structure of reciprocal obligation 'the weaker party is effectively and paradoxically more powerful than the stronger'; this tends to produce 'higher levels of anxiety' that the presumed or aspiring great powers have in a relational context because of the constant need to receive affirmation about their reputational profile (Hwang, 1987, p. 955; Barbalet and Qi, 2013, p. 412; Shih, 2016, p. 690; Kavalski, 2018a, p. 84). This is one of the main distinctions between a guanxi-informed 'relational power' and the 'relational power' 25 model developed by Robert Dahl and David Baldwin (Barbalet and Qi, 2013; Azmanova, 2018).

Thus, the interdependence, mutuality, and reciprocity characterizing guanxi accord social relations much greater significance and relations are often seen as ends in and of themselves rather than means for realizing various individual goals. Maintaining 'group harmony and integrity is much more important than is insisting on disruptive equity' (Hwang, 1987, p. 956). A central feature of guanxi's network of reciprocal obligation is the claim that 'the self so conceived is not a static structure but a dynamic process. It is a center of relationships, not an enclosed world of private thoughts and feelings. It needs to reach out, to be in touch with other selves, and to communicate through an everexpanding network of human relatedness' (Tu, 1985, p. 133). The key 
inference is that participants in a guanxi perceive each other to be 'role occupants rather than individuals' (Hwang, 1987, p. 945). This assumption challenges all attempts to offer Confucian versions of either constructivism (Qin, 2009, 2011, 2016; Uemura, 2015) or the English School (Zhang, 2015). In other words, what changes in the process of interaction are the roles that actors play, not their identity, subjectivity, and/or individuality. This should not be misunderstood as a suggestion that identities (in contrast to roles) remain immutable. On the contrary, the point here is that by focusing on identities, IR analyses tend to reify misleading representational modes for explanation and understanding that freeze the flow of international interactions into static relationships that actors have ('as if they were those self-same, permanent objects whose interactions with the world produce external circumstantial changes to the objects') (Kavalski, 2018b). In the context of ongoing dynamic change, actors are their relationships. Roles therefore are not about identities (or prescribed by them), but about acting on the world stage - an actor can play any role depending on the circumstances.

Thus (and contra Wendtian forms of constructivism), rather than endogenous, roles are exogenous to actors and emerge in relation to the context of interaction and change over time and space. In fact, the very idea of intentionality itself 'cannot be removed from the context in which it arises' (Wen and Wang, 2013, p. 187); role-demands never emerge in the abstract nor are they pre-given, but are borne out and gain their meaning in the process of interaction. Depending on the social circumstances, an actor can be accommodative and generous (as China seems to be in its interactions with East European or African countries, for instance) and assertive and vengeful (as China seems to act in the South China Sea) all at the same time. The role-centric framing of guanxi underpins not only its malleability (i.e., that it can be used for multiple and diverse purposes), but its potential to engender resilient connections in the context of recognizing and influencing emergent opportunities. Owing to the fluid ways in which these relational roles are lived, guanxi asserts that change rather than stability is an endemic feature of global life.

Both through attrition and accretion and depending on the circumstances, issues, and situations, the guanxi relationship has diverse and contingent iterations which demand ongoing re-examination and 
adaptations from all those involved in its webs of reciprocal implication. Instancing such development are China's practices of 'plurilateral regionalism' (such as the Shanghai Cooperation Organization [SCO]), 'plurilateral embedded orders' (such as support for the Chiang Mai Initiative Multilateralization), 'plurilateral parallel orders' (such as the Asian Infrastructure Investment Bank), and network governance (such as the OBOR policy) (Chen, 2016). Such dynamic multiplicity of interdependent conditioning factors engenders an interpersonal realm whose complexity is only partially known to the participating actors. This outlook calls for a contextual attunement to the transient constel- 10 lations of factors and actors that impact on the content, trajectories, and possible transformations in any social relationship - regardless of whether they occur on interpersonal, regional, or global level. In particular, the long-term orientation of guanxi inserts a modicum of predictability by lowering the transaction costs and ensuring the peaceful resolution of conflicts. The underlying aim is to aid the ability to engage an ever-changing world.

\section{Guanxi and the relational turn in IR}

What would a relational theory of IR look like if we were to imagine it with the help of guanxi? To begin with, the outline of such an endeavor should not appear particularly outlandish (let alone heterotopic) to those attuned to the inescapable condition of mutual encounter defining global life (Kavalski, 2016, p. 559). The contention here is that the encounter with the notion of guanxi offers a relational IR theorizing as an optics which both acknowledges the agency of 'others' and through which meanings are generated contingently through interactions in communities of practice, whose relations are premised on the variable reputations of participants and the necessity for ongoing reiteration of the commitment to do things together. The following paragraphs offer a preliminary unpacking of some of the ways in which the concept of guanxi informs such relational theorizing.

To begin with, while relationality has been mentioned in the Anglophone IR literature earlier, the relational turn that has emerged in the past two decades has been associated with the seminal study by Jackson and Nexon (1999). Drawing on the work of the sociologist Mustafa Emirbayer, Jackson and Nexon distinguish between the 
'substantialist' and 'relational' foundations of theory-building. As a result, they map most of what we call IR theory within the former domain and suggest that the commitment to substantialism provides the common denominator 'cut[ting] across conventional divisions in the field, including theories in all the major "paradigms" of IR' (Jackson and Nexon, 1999, p. 293). Positing the existence of atomistic units (or entities) before relations, the substantialist storytelling of IR asserts that states are almost invariably the ontological priors for any kind of theorization. This outlook then facilitates the entrenchment of the idea that international politics is almost by default anarchical and antagonistic. In other words, the assumption that relations are self-evidently secondary to the primary condition of conflict on the world stage legitimizes the post-ontological contention that peaceful coexistence is possible only through the complete mastery and subjugation of all forms of otherness (i.e., 'domination over everything which is not itself') 15 (Odysseos, 2007, p. xxxi).

It is in this setting that the Sinophone IR community - most prominently, Qin Yaqing - have criticized the Anglophone IR mainstream for its ongoing lack and inability to articulate a theory of relations. Qin faults Jackson and Nexon for their Eurocentric outlook which propounds an equally isolated (and isolationist) 'relations-for-relations sake' approach as that of the substantionalism they seek to debunk (Qin, 2009, p. 14). His broader critique is that the relationality propounded by Jackson and Nexon fails to decenter the monological knowledge production of IR. Thus, the exclusion (and expulsion) of 25 'non-Western' perspectives and experiences perpetuated from this account of relationality fails to trouble the underlying 'individualistic rationality' (of substantialist IR) - which Qin defines as the underlying 'metaphysical component of the theoretical hard core' of Anglophone IR (Qin, 2016, p. 34). While Qin indeed might be correct about the Eurocentric underpinnings of Jackson and Nexon's model, his relational theory of world politics offers little room for acknowledging (let alone working creatively with and through) the 'circles of reciprocal implication' engendered by relationality (Coles, 2016, p. 49).

Guanxi implies both a propensity and a capacity for living with and 35 in ambiguity. In this respect, it provides a 'relational' (as opposed to 'rule-based') framework for the meaningful contextualization in the shifting patterns of global life (Qin, 2011, pp. 129-153). What passes 
for world affairs in such a context is not about 'the application of abstract norms to cases,' but about 'a set of particular international relationships, with concrete obligations defined within the context of each relationship' (Womack, 2008, p. 265). This understanding reframes power away from its association with the material possession of capacities for influence (regardless of whether they are coercive or not), but as a 'relational practice' (Qin, 2009, p. 9). This then becomes the centerpiece for a 'logic of relationships' animating global life (Womack, 2008; Kavalski, 2013; Shih, 2016). Such a logic assumes that 'while the future is unknown, the partners in the future are the same as in the past and present. Therefore, the bottom line is that both sides feel that they are better off if the relationship continues - this is the minimum meaning of 'mutual benefit'. A normal relationship does not require symmetry of partners or equality of exchanges, but it does require reciprocity [i.e., respect for the other]' (Womack, 2008, pp. 295-297). The relationality framed in this way is not about the hubris that we can control outcomes and steer history, but about care, attentiveness, humility, and responsibility to others.

It should be stated at the outset that such framing should not be misunderstood as an indication of a selfless outlook on global life, but as an effective strategy for managing a hyper-social environment. This assertion recalls the qualification from the introductory section that the present analysis of the relational universe of guanxi does not draw on Chinese foreign policy practice, nor imply that China's international interactions are informed by guanxi. Instead, the logic of relationships outlines a social context for action in which goals can be achieved through an active, committed, and responsible involvement in world affairs that takes into account the broader context of international interactions and the specificities of a particular interactive environment (regardless of whether it is bilateral or multilateral). This pattern demands both contextual sensitivity and an ongoing commitment to the deliberate practices of relationality from all sides involved in the interaction. Such 'ecology of action' backstops an ethic of 'living otherwiserelationally' (Rojas, 2016, p. 370) - namely, the cultivation of relational practices and circumstantial adaptations responsive to the emergent, his- 35 torically contingent, and self-organizing character of global life.

Unsurprisingly, therefore, a key feature of guanxi's dynamic outlook is the emphasis on harmony (Horesh and Kavalski, 2014, pp. 230-248; 
Nordin, 2016). Thus, just like the metaphor of anarchy backstops a self-help international system prioritizing material capability, the narratives of harmony outline a pattern of order premised on reciprocal relationships which pays premium for the dedicated cultivation of connectivity in the context of an ongoing demonstration of respect for the other. The point here is that guanxi ties are volitional - actors intentionally commit to the interaction by demonstrating their willingness to exercise self-restraint. Such guanxi dynamics should not be misunderstood as altruism; on the contrary, they are pointedly strategic for instance, China's global outreach can be read as a policy of 10 pre-emptive interaction intent on allaying the concerns of other international actors and motivated by 'the hope for less future loss by preserving positive relations with all concerned parties' (Huang and Shih, 2014, p. 20).

In such a relational setting, agency (especially, international agency) is not about the intentional projection of self-interest, but about strategic receptivity - i.e., 'knowing oneself insofar as one is related to others, and knowing others insofar as others are related to oneself' (Wen and Wang, 2013, p. 192). Rather than impeding the policy process, such contextual attunement discloses the unexpected opportunities made possible by the pattern of guanxi - for instance, as evidenced by the unintended evolution of the Shanghai-5 into the OBOR initiative via the SCO. This development reflects the way in which the reciprocity, complementarity, and correspondence of guanxi-relationality can change both perceptions of agency and context by creating unanticipated, visible, and committed coordination between two or more actors. Order in this setting is a dynamically constituted outcome of social interactions and participatory cognition, which is fluid, contextsensitive, and temporal. Thus, what began as a single-issue relationship (border demarcation between China and the Central Asian states) 30 addressed through a series of bilateral diplomatic arrangements (the Shanghai-5), grew into a multilateral organization (the SCO), which then spilled over into the most extensive connectivity project the world has seen (OBOR).

The inference here is that international agency emerges in a commu- 35 nity, not in a vacuum. In particular, it is communities of practice that locate guanxi's logic of relationships. The animating force of such relationality appears to be a commitment to the practice of doing things 
together which affords ongoing opportunities for interpretative articulation and re-articulation of international exchanges that can engender, enhance, and reaffirm the reputational profile of participating actors an aspect that can explain China's general aversion to the imposition of conditionality on its partners. The accent is on the strategic value of maintaining the relationship rather than on the pursuit of immediate gains. In this respect, the interactive dynamics of communities of practice stimulate new and contextual definitions of the 'common good' by drawing attention to the distinct roles and positions that international actors take in diverse spatial and temporal contexts. In this process, 10 communities of practice reveal a new way of being present in the world through the binding power (as well as social energy) of deliberate interactions.

Thus, as the hub of social knowledge and social life, guanxi-ties intimate that shared understandings are not imposed as rules, rights, or obligations, but emerge in, from, and through the very process of interaction. Guanxi, thereby, presages an understanding of international action and agency - both cognitively and affectively - as simultaneously shaped and mediated by ethical obligations and commitments to others (the structure and content of which is acquired through the very relationships by which ethical obligations and commitments to others are disclosed). At the same time, the context provided by communities of practice rearticulates agency as being compelled by the demands made by the other participants in the interaction. This requires skills for living (if not, thriving) in a social environment beyond the control of any of the participating actors. Such relationality is not zero-sum - i.e., 'the debit and credit sides of this [relational] balance sheet are never in equilibrium' - because this would spell the end of guanxi (Yeung and Tung, 1996, p. 20). What is important emerges not as a result of individual decisions, but relationally in the process of interactions with others and becomes meaningful in the social context of doing things together with them.

The currency of such relationality is not legitimacy (as most IR scholars seem to suggest), but reputation. The cultivation of reputation (a feature which IR observers tend to subsume within the analyses of status) is probably the key aspiration of guanxi. As Jack Barbalet cogently observes, reputational standing is a social resource and not an economic one. Thus, guanxi is deployed not with the aim to gain access 
to economic or political resources, but is 'primarily directed to acquiring and expending social resources' (Barbalet, 2015, p. 1044). Not only that, but the strategic aim of guanxi is to enhance the reputation for trustworthiness of actors by providing a series of situations in which they can continuously enact (as well as be evaluated on) their 'meeting the expectations of others' (Ho, 1976, p. 873). Under the Confucian understanding of harmony, losing the trust of the other participating actors is the greatest danger to the relational world order enacted through the practices of guanxi (Huang and Shih, 2014, p. 19). In this setting, China's insistence on the harmonious respect for the other can be read as nothing short of a strategic desire for the recognition of its reputational profile on the world stage.

\section{Conclusion: the relationality of post-Western IR}

The preceding sections demonstrate the promise from drawing on the Chinese concept of guanxi in order to amplify the intrinsic relationality of global life and the realms of IR. In contrast to the dualistic bifurcations that dominate IR imaginaries, the concept of guanxi illuminates that the complex patterns of global life resonate with the fragility, fluidity, and mutuality of global interactions, rather than the static and spatial arrangements implicit in the fetishized currency of self-other/ center-periphery/hegemon-challenger models underpinning the binary metanarratives of IR. This is a major departure from the current state of the art on relationality in IR; rather than looking at dyadic sets of relations as well as the identities and capacity of individual actors, the preceding engagement with guanxi inheres an IR pivoted on webs of figurations intertwined by a conscious and strategic search for relations with others. As the sociologist Fei Xiaotong (1992) points out, the relational model (guanxi moshi) of knowledge production relies on engaging with and learning form the experience of others. Known as tui 'pushing or extending ... to reach out to the world', such sensemaking turns 'the unknown [into] the familiar' through the sociality of ongoing interactions - namely, 'first we encounter, then we practice' (Fei, 1992, pp. 42-67). In this respect, actors (and their agency) have effects only to the extent that they are in relations with others. Thus, owing to the dynamic nature of such interactions, what passes for world order is not only constantly changing, but demands ongoing 
commitment to participating in and maintaining relations. With this in mind, the concluding section of the article offers a relational reading of China's rise before sketching some of the implications for postWestern IR theorizing.

The heuristics of guanxi suggest that shifts in material capabilities do not in and of themselves reveal much about the patterns of world affairs unless they are assessed in their interactive environment. Drawing on the narratives of power transition, the story of China's rise takes as its point of departure the dyad of hegemon-challenger the former unwilling to relinquish its leadership position, while the latter has growing capacities and aspirations to claim it (by force, if necessary). The impoverished Cartesian outlook of this IR narrative prescribes the transformation of generic fears into specific threats which then inform policies of alliance-building or offer opportunities for military conquest. It is therefore not surprising that more often than not the discussion of China's rise turns into a conversation about if and when a Sino-American military conflict would likely erupt. The alternative narrativization provided by a relational IR theorizing treats China's rise as a socially negotiated practice (for which power transition offers, at best, only a partial label). It would be a mistake to 20 assume that such relational reading proscribes antagonism or confrontation. (Radical) Difference - such as the one associated with the phenomenon of China's rise and the episteme of guanxi - is the very condition for the possibility of emergence and innovation in global life. Thus, rather than something that needs to be controlled, subjugated, 25 or denied, the difference of China's rise can be translated through the relational lens of 'interdependence-in-antagonism' - a normative stance that treats cooperation and competition as corresponding forces which underpin the mutual dependence of all those inhabiting global life (Patomäki, 2002, p. 62; Kavalski, 2017, p. 163). As such, rather than a condition requiring ongoing securitization, difference discloses 'a relation that brings disagreements into the conversation' and forces the mechanisms that proscribe 'other forms of being and knowing to become visible' (Rojas, 2016, p. 380; Walton and Kavalski, 2017, pp. 207-221).

In terms of the epistemic difference of guanxi, the claim here is that nonbinary relationality has become a defining feature of post-Western IR theory-building and knowledge production (Bilgin and Ling, 2017; 
Chen, 2014; Cho, 2015). It seems few today would dispute that the disciplinary inquiry of Anglophone IR is indelibly marked by the 'colonial signs' of its Eurocentric makeup. Not only that, but the 'apple pie' flavor that IR acquired in the context of its Cold War transformation into an 'American social science' seems to have made the discipline even more inimical toward encounters with the various non-Western others that its outlook consciously occludes (Kavalski, 2012, p. 19). In an attempt to trouble the juxtapositions of temporal and geographical difference that still seem to stump any IR alternative prefixed by a 'non-' or a 'post-', this article has posited the centrality of relationality as a distinguishing feature of all such projects. In this setting, the relationality lens helps outline the contested terrain of post-Western IR as a space for dialogical learning, which encourages engagement with the possibilities afforded by the interactions of multiple worlds and privileges the experiences and narratives of neither of them (Kavalski, 2016, 15 p. 553).

Such mode of theorizing allows building solidarity between likeminded projects, targeting the silencing, hegemony, patriarchy, and violence of the mainstream by treating them as second-order aspects deriving from a first-order problematique - IR's poignant ontological and epistemic lack of relationality (Barbalet, 2015; Kavalski, 2015a). It is the very denial of relationality (first-order issue) that perpetuates the imperial, patriarchal, and racist attitudes (second-order issues) of IR. It is in this vein that the attack on the latter, that so much of critical, feminist, and postcolonial theorizing undertakes, overlooks the very condition of its possibility - the lack of relationality in IR. What this means is that the IR mainstream has been dominated by an atomistic understanding of global life which prioritizes fixed units of analysis (nation states) and their discrete dyadic interactions (conflict/balancing in the context of anarchy). Yet, at no point is the option of a sociability infused with the contingent opportunities inherent in the encounter with the other acknowledged in this narrative; let alone the potential that the phenomena and processes animating world affairs are mutually co-constituted in relation to one another (Kavalski, 2015b). Instead, global life is envisioned as a domain of disconnected states, infamously 35 imagined as billiard balls - 'closed, impermeable, and sovereign unit[s], completely separated from all other states' (Wolfers, 1962, p. 19). 
A relational IR theorizing - which is nonbinary in the sense that it does not treat the West and the non-West as discrete and disconnected homogenous opposites, but intertwined and mutually constitutive webs of interactions - proposes a molecular outlook whose unit of analysis is relations (rather than actors) and their multiple triadic dynamics (which open numerous and numinous points of and possibilities for interaction). IR theorizing is not merely about the provision of knowledge (in the sense of a positivistic measuring exercise); rather, it is about forming than purely informing; it is about the art of living than de-contextual and detached abstract thought; it is about doing ethical considerations in theory and in practice. In other words, what makes post-Western IR narratives 'post-Western' is their emphasis on irruptive relationality namely, things in global life are not merely interconnected, but that they gain meaning and significance within complex webs of entanglements and encounters with others. The proposition here is that the disciplinary mainstream (and particularly its Anglophone variants) has, on the one hand, evaded the need to recognize that there are dynamics which are not only unknown, but probably cannot ever be meaningfully rendered comprehensible, and, on the other hand, has stifled endeavors that can engage in thoughtful deliberation of the discontinuities, unpredictability, and nonlinearity of global life. It is in this setting that this study posits post-Western IR as necessarily contextual, incoherent, and socially mediated - just like the everyday patterns and practices of the global life it intends to explain and understand. The emphasis on relationality thereby acts as a reminder that IR knowledge, just like any knowledge, 25 is acquired and mediated relationally through diverse sets of practices; as such, the myriad interpretative entanglements of people, powers, and environments (as well as their complex histories, cultures, and agency) stimulates an awareness of the dynamically intertwined contingencies through which different paradigms have come to be articulated and assembled in ways that could have been - and could become significantly different (Coles, 2016, p. 121; Kavalski, 2017, p. 167).

Thus, the curious and provocative entanglements with the complexity of global life invoke the pluriverse of possible worlds. It is relations that are not only at the heart of explaining and understanding the world, but also central to its observation and encounter. The epistemic (and ethical) verso of relational IR is about the cultivation of attentiveness to the self-organizing, shifting, and historically and geographically 
contingent realities of global life. Such attentiveness will make IR research doubtlessly messy. Yet, such messiness is needed if IR is to recover a disposition for encounter and engagement with the currents, trends, and voices that are occluded, uncomfortable, and not easily digestible by established paradigms. Thus, the encounter with the concept and practices of guanxi invokes the complexity of possible worlds uncovered by relational IR theorizing. After all, what is IR as a discipline if not the conscious exploration and encounter with the interstitial and relational. China's rise - as a phenomenon, narrative, and a set of processes - reminds us that global life is not necessarily a place where in- 10 ternational actors merely find themselves in; it is where they get lost in the complexity of interactions and relationships.

\section{References}

Azmanova, A. (2018) 'Relational, structural, and systemic forms of power', Journal of Political Power, 11(1), 68-78.

Barbalet, J. (2015) 'Guanxi, tie strength, and network', American Behavioural Scientist, 59(8), 1038-1050.

Barbalet, J. and Qi, X. (2013) 'Paradox of power', Journal of Political Power, 6(3), 405-418.

Beier, J.M. (2005) IR in uncommon places. Basingstoke: Palgrave.

Bilgin, P. and Ling, L.H.M. (2017) Asia in international relations. London: Routledge.

Carlson, A. (2010) 'Moving beyond sovereignty', Journal of Contemporary China, 20(68), 89-102.

Chen, C.-C. (2014) 'The absence of non-Western Ir theory in Asia', 25 International Relations of the Asia-Pacific 11(1), 1-23.

Chen, Z. (2016) 'China, the EU and the fragile world order', Journal of Common Market Studies, 54(4), 775-792.

Cho, Y.C. (2015) 'Colonialism and imperialism', Cambridge Review of International Affairs 28(4), 680-700

Chowdhry, G. (2007) 'Edward Said and Contrapuntal Reading', Millennium $36(1), 101-116$

Coe, A. (2009) Chop Suey. Oxford: Oxford University Press.

Coles, R. (2016) Visionary Pragmatism. Durham, NC: Duke University Press.

D'Aoust, A.-M. (2012) 'Accounting for the politics of language in IR', 35 Journal of International Relations and Development 15(1), 120-131. 
Fei X. (1992) From the Soil: Foundations of Chinese Society. Berkeley, CA: University of California Press.

Ford, C. (2010) Mind of Empire. Lexington, KY: University Press of Kentucky.

Foucault, M. (2002) The Order of Things. London: Routledge.

Gold, T., Ghine, D. and Wank, D. (2002) Social Connections in China. Cambridge: Cambridge University Press.

Ho, D.Y.F. (1976) 'On the Concept of Face', American Journal of Sociology, 81(4), 115-139.

Horesh, N. and Kavalski, E. (2014). Asian Thought on China's Changing 10 International Relations. Basingstoke: Palgrave.

Huang, C.-C. and Shih, C.-y. (2014) Harmonious Intervention. London: Routledge.

Hwang, K.-k. (1987) 'Face and Favour', American Journal of Sociology, 92(4), 944-974.

Jackson, P. and Nexon, D. (1999) 'Relations before states', European Journal of International Relations, 5(3), 291-332.

Jenco, L. (2016) Chinese Thought as Global Theory. Albany, NY: SUNY Press.

Kavalski, E. (2009) China and the Global Politics of Regionalization. London: Routledge.

Kavalski, E. (2012) Central Asia and the Rise of Normative Powers. New York: Bloomsbury.

Kavalski, Emilian (2013) 'The struggle for recognition of normative powers', Cooperation and Conflict, 48(2), 247-267.

Kavalski, E. (2015a) World Politics at the Edge of Chaos. Albany, NY: SUNY 25 Press.

Kavalski, E. (2015b) Encounters with World Affairs. London: Routledge.

Kavalski, E. (2016) 'Relationality and its Chinese characteristics', China Quarterly, 226, 551-559.

Kavalski, E. (2017) 'Towards a relational knowledge-production in interna- 30 tional relations', Korean Political Science Review, 51(6), 147-170.

Kavalski, E. (2018a) The Guanxi of Relational International Theory. London: Routledge.

Kavalski, E. (2018b) 'The normative dimension of EU-China relations: Acquis Communautaire vs Guanxi, in Bersick S. et al. (eds), Routledge Handbook 35 on EU-China Relations. London: Routledge.

Kavalski, E. (2018c) 'Chinese Concepts and Relational International Affairs', All Azimuth, 7(1), 87-102.

Kavalski, E. (forthcoming) 'The Guanxi of Relational International Affairs', Chinese Political Science Review. 
Kowalzig, B. (2005) 'Performances of Theoria', in Elsner. J and Rutherford I. (eds), Pilgrimage in Antiquity, pp. 41-72. Oxford: Oxford University Press.

Ledeneva, A. (2008) 'Blat and Guanxi', Comparative Studies in Society and History, 50(1), 118-144.

Liu, L.H. (1995) Translingual Practice. Stanford, CA: Stanford University 5 Press.

Medhurst, W.H. (1838) China: Its State and Prospects. London: John Snow.

Mignolo, W. (2002) 'The Geopolitics of Knowledge', South Atlantic Quarterly, 101(1), 57-96.

Mokry, S. (2016) 'Chinese International Relations', in Peters. I and 10 Wemheuer-Vogelaar W. (eds), Globalizing International Relations, pp. 135-164. Basingstoke: Palgrave.

Morefield, J. 2014. Empires Without Imperialism. Oxford: Oxford University Press.

Nightingale, A. (2004) Theoria in Its Cultural Context. Cambridge: Cambridge 15 University Press.

Nordin, A. (2016) China's International Relations. London: Routledge.

Odysseos, L. (2007) The Subject of Coexistence. Minneapolis, MN: University of Minnesota Press.

Pan, C. (2012) Knowledge, Desire, and Power in Global Politics. Cheltenham: 20 Edward Elgar.

Pan, Z. (2016) 'Guanxi, Weiqi and Chinese strategic thinking,' Chinese Political Science Review, 1(1), 303-321.

Patomäki, H. (2002) After International Relations. London: Routledge.

Pye, L. (1982) Chinese Commercial-Negotiating Style. Cambridge, MA: 25 Oelgeschlager, Guun, and Hain.

Qin Y. (2009) 'Relationality and processual construction', Social Sciences in China, 30(3), 5-20.

Qin Y. (2011) 'Rule, rules, and relations', Chinese Journal of International Politics, 3(2), 129-153.

Qin Y. (2016) 'Relational theory of world politics', International Studies Perspectives, 18(1), 22-47.

Rojas, C. (2016) 'Contesting the colonial logics of the international', International Political Sociology, 10(4), 369-382.

Shih, C.-y. (2016) 'Affirmative balance of relationship', International Studies 35 Review, 18(4), 681-701.

Solomon, R. (1975) Revolution Is Not a Dinner Party. New York: Anchor.

Solomon, R. (1995) Chinese Political Negotiating-Behaviour. Santa Monica, CA: RAND.

Tickner, A. (2003) 'Seeing IR differently', Millennium, 32(3), 61-74 
Tu, W.-m. (1985), Confucian Thought. Albany, NY: SUNY Press.

Uemura, T. (2015) 'Understanding Chinese Foreign Relations', International Studies Perspectives, 16(3), 345-365.

Vale, Peter (2014) 'If international relations lives on the street', International Relations 28(2), 141-158.

Vucetic, S. (2011) The Anglosphere. Stanford, CA: Stanford University Press

Walker, A. (2012) China Calls. Lanham, MD: Rowman \& Littlefield.

Walton, D. and Kavalski, E. (2017) Power Transition in Asia. London: Routledge.

Waltz, K. (1979) Theory of International Politics. Reading, MA: 10 Addison-Wesley.

Weakland, J. (1950) 'Action in Chinese culture', Psychology, 13(3), 361-370.

Wen, H. and Wang, H. (2013) 'Confucian cultural psychology', Culture \& Psychology, 19(2), 184-202.

Wolfers, A. (1962) Discord and Collaboration. Baltimore, NJ: JHU Press.

Womack, B. (2008) 'China as a normative foreign policy actor', in Tocci N. (ed.), Who Is a Normative Foreign Policy Actor?, pp. 265-300. Brussels: CEPS.

Yang, M.M. (2002) 'Resilience of guanxi', China Quarterly, 42(170), 459-476.

Yeung, I.Y.M. and Tung, R.L. (1996) 'Success in Confucian societies', 20 Organizational Dynamics, 25(2), 54-65.

Zhang, F. (2015) Chinese Hegemony. Stanford, CA: Stanford University Press. 